\title{
Evaluation of geopressure regime in an onshore Niger delta field of Nigeria
}

\begin{abstract}
Over pressure regime experienced in onshore Niger Delta is always as a result of drilling limitations such as kicks, blow-outs, borehole instability, stuck pipe, and lost circulation. Inaccurate prediction of over pressure can lead to well design failure and hazards that is associated with drilling campaign. Stable and trouble free drilling plan can be achieved through a thorough over pressure prediction prior to drilling exercise. We adopted Eaton's and Ben-Eaton model in order to estimate and also interpret pore pressures and fracture gradient regimes in the study location. The techniques presented included using velocity against density plots to determine overpressure mechanisms, using measured pressure data, checkshots, conditioned petrophysical well logs and geological interpretation to interpret shale pressures using Eaton's model and fracture gradient prediction. The overburden stress, normal compaction trends (NCT) and shale velocity trends were generated from the volume of shale, density, and sonic logs. Pore pressures in the wells were then predicted using Eaton's model and compared with measured pressures (RFT data). The results obtained from the analysis reveal that wells B and A experience top of high overpressures $(>0.71 \mathrm{psi} / \mathrm{ft})$ at a depth of about $15,400 \mathrm{ft}$ and 11,900 ft (TVDSs) respectively. The measured pore pressures (MPP) at the two well locations and the predicted pore pressure were related; this established the fact that the pore pressure prediction model used in this study is appropriate in line with the local geology. Outcome of this study also illustrates that the seals in the wells have good retention capacities and hence good trap integrity (or drilling margin) except at higher depths judging from fracture gradient results.
\end{abstract}

Keywords: Geopressure, evaluation, niger delta, blowout, eaton, overburden stress, petrophysics
Volume I Issue 5 - 2017

\author{
Chukwu GU \\ Department of Physics, Michael Okpara University of \\ Agriculture, Nigeria
}

Correspondence: Chukwu GU, Department of Physics, Michael Okpara University of Agriculture, Umudike-Umuahia, Nigeria,Tel +2348025691478, Email chukwug@yahoo.com

Received: November 10, 2017 | Published: December 12, 2017

\section{Introduction}

Geopressure evaluation or prediction is an important exercise that must be carefully estimated when planning a drilling campaign. Formations of high pressure regime can be experienced in several areas within the bore hole depths. Being unaware of these areas that experience high pressure regime can create many uncontrolled events such as blow outs that may lead to human and material loss within the location. Geopressure regime is the pressure that is cause by the pore fluids within the pore spaces of the subsurface. At any depth, the overburden pressure is the summation of weight grains and the pore pressure at that depth. ${ }^{1}$ Subsurface formation that is over pressured is characterized by the pore fluid pressure that is significantly below or above the normal hydrostatic pressure at a given depth ${ }^{1}$ (Jiao, et al 1998, Dickinson, 1983). For safety, economic and efficient way of well drilling requires an accurate evaluation of the over pressure regime. Pore pressures are easily predicted for normally pressured sediments but challenging when the sediments are abnormally pressured. ${ }^{1}$ This accurate geopressure evaluation is necessary for an efficient drilling plan in order to choose proper casing points and also design a better casing program that will allowed for a total control of the drilling and completion program. ${ }^{1,2}$

Geopressure are evaluated through the use of the relevant subsurface data, also having knowledge of burial, stress and temperature histories, rock types and their distributions and subsurface structure and reservoir connectivity with the formation will be an advantage..$^{1,3}$ Predicting geopressure is one of the biggest challenges that is facing the oil industry, particularly as exploration moves into the deep- water areas. It has emerged from years of research that the origin of overpressure and its effect on the petroleum system are complex and difficult to quantify. ${ }^{1,3}$ In Niger Delta field, where the shallow region of the sedimentary base has a high sand accumulation, the onset of overpressure is deeper, but the rate of the pressure-transition zone is much more rapid which contribute to drilling failures (Swarbrick et al., 2011). There are several mechanisms responsible for over pressure regime: which includes, disequilibrium compaction, load transfer, fluid expansion and buoyancy pressure. Disequilibrium compaction is attributed to be the main cause of overpressures that are generated in most fine grained sedimentary basins (Dickson, 1953). ${ }^{4}$

The overpressure mechanism must be established before the pore pressure evaluation. This will aid in determining the best model that can be used in prediction. Disequilibrium compaction and fluid volume expansion or unloading has been the main generating mechanism for overpressure. ${ }^{5}$ These results from high sedimentation rates of low permeability rocks, such as mud rocks and sand shale contributes to under watering of the sediments. Rapid increase in compressive stress is attributed by burial or tectonic forces which cause the sediments to compact and also expel fluids. If the fluids cannot be expelled sufficiently rapidly, some of the compressive load is borne by the pore fluids, and then overpressure develops (Terzaghi and Peak, 1948). ${ }^{5}$ Fluid expansion effective stress overpressure mechanism which is generally termed as secondary overpressure mechanism requires a very low net permeability seal and relatively high regional geothermal gradient of about $25^{\circ} \mathrm{C} / \mathrm{Km} \cdot{ }^{6,7}$ Overpressure generation mechanisms can be detected using velocity and density analysis. Shale velocity against density cross-plots can be used to distinguish 
between overpressures generated by disequilibrium compaction and overpressure generated by fluid expansion. ${ }^{7,8}$ The main purpose of this study is to evaluate the geopressure regime that is associated with onshore Niger Delta field.

\section{Materials and methods}

The data that were used for this research are, wire line logs [Gamma ray, Density, Sonic, Resistivity, Calliper and Neutron logs], direct measured pressured data [RFTs, MDTs, LOTs, Mud weights and information from Well Drilling reports], well information in other words: deviation data, well tops, rig floor elevation, fluid fill, lithology, water depth and well checkshots. Wireline logs from two oil and gas bore hole were used in this study. The suite of wireline $\log$ data comprises of sonic $\log$, density log, resistivity log, caliper $\log$, porosity $\log$, and gamma ray $\log$. The well logs include two exploration wells: A side-track over pressured well (WELL A) with a total depth of approximately $14,500 \mathrm{ft}$, and a deviated overpressure well (WELL B) with a total depth of approximately 15,900 ft. The logs include caliper, gamma ray, porosity, shale volume, resistivity, density, P-wave and acoustic impedanceThe depth of the logs are originally in true vertical depth (TVD) but will be converted to true vertical depth subsea (TVDss) using the deviation survey and also converted to two way travel time (TWT) using the checkshots. The main workflow carried out in this work include: well log editing or conditioning, NCT, OBP and shale velocity trends generation, PPP in shales, Comparism with MPP, Fracture Gradient Pressure and Interpretation.

The approach used in the study is an integrated one which predicts pressures and fracture gradient below well-known depths from measured pressure data, checkshots, sonic logs and geological interpretation. Normal compaction trend (NCT), OBP and shale velocity trends were generated from the volume of shale, density and sonic logs. Eaton's empirical method was adopted for pore pressure prediction in order to manually pick the prediction points within the shale intervals. The Eaton method uses a direct transform from velocity to pore pressure, estimates the vertical component of the effective stress $\sigma$ from the seismic velocity $\mathrm{v},{ }^{9}$

$\sigma=\sigma_{\text {Normal }}\left(\mathrm{V} / \mathrm{V}_{\text {Normal }}\right)^{\mathrm{n}}$

Where $\sigma_{\text {Normal }}$ and $V_{\text {Normal }}$ in this equation are the vertical effective stress and seismic velocity expected if the sediment is normally pressured, while $\mathrm{n}$ is an exponent that describes the sensitivity of velocity to effective stress. ${ }^{9}$ The pore pressure is then given by Terghazi as (Terghazi, 1948):

$\mathrm{P}=\mathrm{S}-\sigma$

Putting equation (1) into (2), we have:

$$
\begin{aligned}
& \mathrm{P}=\mathrm{S}-\left(\sigma_{\text {Normal }}\right)\left(\mathrm{V} / \mathrm{V}_{\text {Normal }}\right)^{\mathrm{n}} \\
& \text { But } \sigma_{\text {Normal }}=\mathrm{P}_{\text {obs }}-\mathrm{P}_{\text {hyd }} \\
& \mathrm{P}=\mathrm{S}-\left(\mathrm{P}_{\text {obs }}-\mathrm{P}_{\text {hyd }}\right)\left(\mathrm{V} / \mathrm{V}_{\text {Normal }}\right)^{\mathrm{n}}
\end{aligned}
$$

Where: $\mathrm{P}$ is the Predicted (shale) pore pressure

\section{$\mathrm{S}$ is Overburden pressure (rocks and fluids)}

$\mathrm{n}$ is normal hydrostatic pressure (fluids) which is $\mathrm{P}_{\mathrm{obs}}-\mathrm{P}_{\text {hyd }}$

$\mathrm{P}_{\text {obs }}$ and $\mathrm{P}_{\text {hyd }}$ are the Overburden pressure and Hydrostatic pressures respectively.

\section{$\mathrm{V}=$ Measured Interval velocity (seismic data)}

$\mathrm{V}_{\text {Normal }}=$ normally compacted shale velocity (from the normal compaction trend line)

$\mathrm{P}, \mathrm{S}$ and $\mathrm{V}_{\text {Normal }}$ are empirically derived values from relevant well data and the interval velocity $\mathrm{v}$ is derived from seismic processing.

According to Sayers et al., (2002), to use Eaton's method, the deviation of the measured velocity from that of normally pressured sediments $\mathrm{V}_{\text {Normal }}$ must be estimated. Usually, a suitable parameterized expression for $\mathrm{V}_{\text {Normal }}$ will be chosen, and the parameters are obtained by fitting to the shallow velocities, assuming the shallow sediments were normally pressured. However, high pressure often begins at shallow depths thus invalidating this approach. The assumption that shallow sediments are normally pressured is also unnecessary, because the parameters defining $\mathrm{V}_{\text {Normal }}$ may be determined by an inversion of existing pressure data (Sayers et al., 2002).

Pore pressure prediction (PPP) in shale was carried out and compared with the measured pore pressure (MPP) in shale from the two wells. The fracture pressure gradients of the wells were also estimated at same depths. This multi-well function was used in constructing the normal trend models from input log data of any type, and used for Pore Pressure profiles generation. In order to generate normal compaction trend (NCT) a model is calculated from the input $\log$ data from normal compaction fit. The normal compaction fit is then used together with the input log, hydrostatic and lithostatic to calculate pore pressure $\log$ for each of the wells. Shale volume cut-off was used to set either for the whole depth range, or separate cut-offs for each of the depth interval. Shale volume log represents the volume fraction of shale as measured or inferred from formation properties. During this study, the shale volume was calculated from Gamma ray $\log$. Shale is usually more radioactive than sand or carbonate, gamma ray $\log$ can be used to calculate volume of shale in porous reservoirs. The volume fraction of clay in a rock (Vclay) may be determined from a gamma-ray log by setting gamma-ray values representative of clean sand and pure clay. According to Larionov (1969) for Tertiary rocks, volume of shale is given as:

$\mathrm{Vsh}=0.083\left(2^{3.7 \mathrm{IGR}}-1\right)$

where GR is gamma ray log.

The overburden pressure, (OBP) is the geostatic or lithostatic pressure at any depth, which is assumed to be given by the combined weight of the rock matrix and the fluids in the pore space overlying the interval of interest. This may be calculated as an integral of density as follows:

$$
O B P=g \int_{0}^{z} \rho(z) d z
$$

The over pressure detection was estimated after the calculation of the over burden pressure (OBP), Shale volume and normal compacted trends, the sampling of the values of these parameters was made manually along the vertical shale section with thick shale units. To achieve this, a log panel is loaded with derived log which aids in manual tracking of the values within shale units. Lastly Ben-Eaton equation was adopted for fracture gradient prediction and it can be given as follows:

$$
\mathrm{F}=(\mathrm{S}-\mathrm{P}) / \mathrm{D} \times(\Upsilon / 1-\Upsilon)+\mathrm{P} / \mathrm{D}
$$

Where $\mathrm{S}=$ Overburden stress, psi 
$\Upsilon=$ Poisson's ratio

$$
\mathrm{D}=\text { Depth }
$$

\section{Result}

Well logs were used in this analysis. The well logs include two exploration wells: A side-track over pressured well (WELL A) with a total depth of approximately $14,500 \mathrm{ft}$, and a deviated overpressure well (WELL B) with a total depth of approximately 15,900ft (Figures 1) (Figure 2). Petrophysical quality control was carried out on the logs. The logs were de-spiked, edited to remove spurious events and up scaled using blocking routines in order to reduce the scatter in the lithology, fluid and unloading analyses. When logs are loaded, the defaults units are usually measured depth (MD), it was necessary to convert measured depth (MD) to true vertical depth (TVDss) which represents the true depth of the well to the sea level datum. Position Sets are used to transform from Measured Depth (MD) to True Vertical Depth Subsea (TVDSs). The position contains the trajectories for a deviated well and would convert the logs to their true depth. The position sets is in the following formats: MD-Dip-Azimuth. The cross-plots for the two well logs are shown below. They are compared with the model by Swarbrick ${ }^{10}$ and the interpretation revealed that the two well have compaction disequilibrium as their overpressure generating mechanisms (Figure 3) (Figure 4).

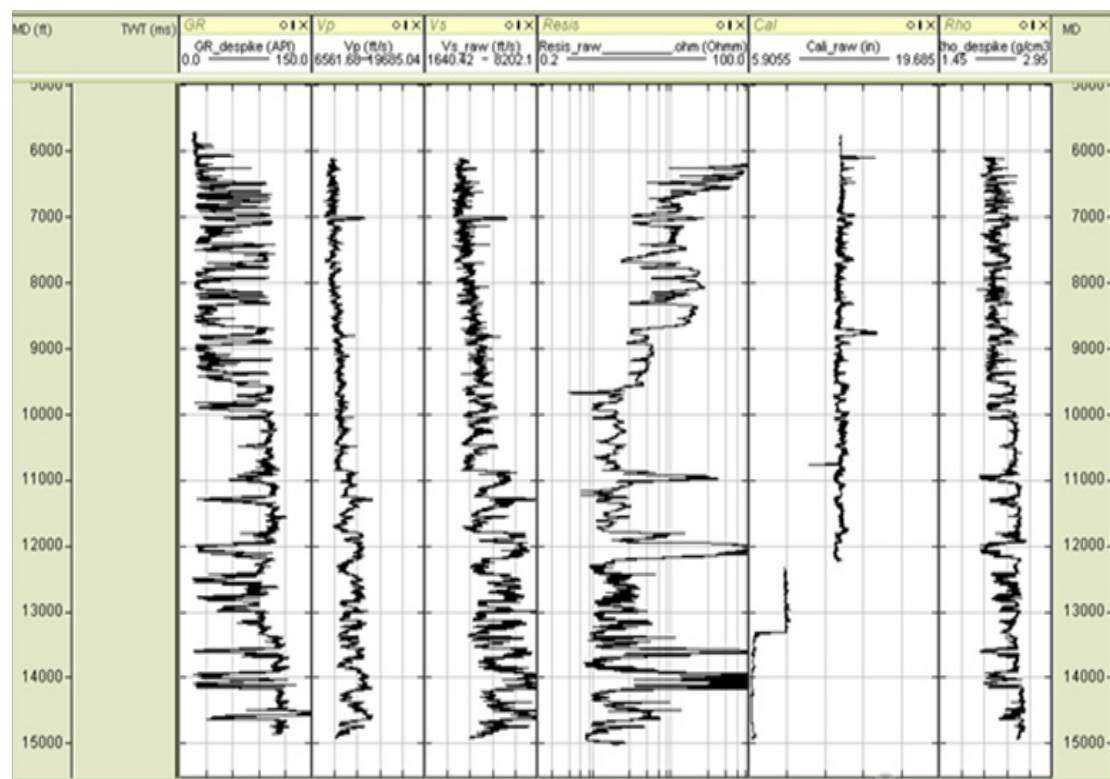

Figure I Well A showing suite of logs.

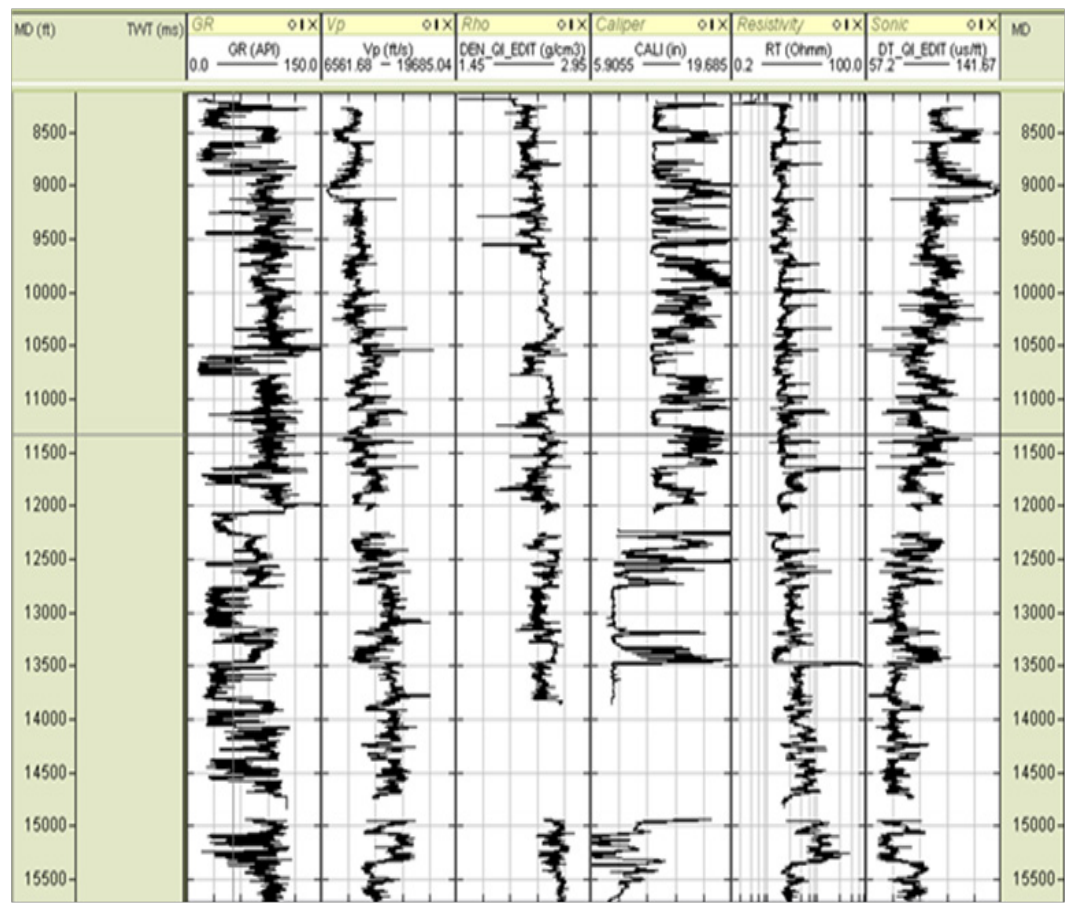

Figure 2 Well B showing suite of logs. 


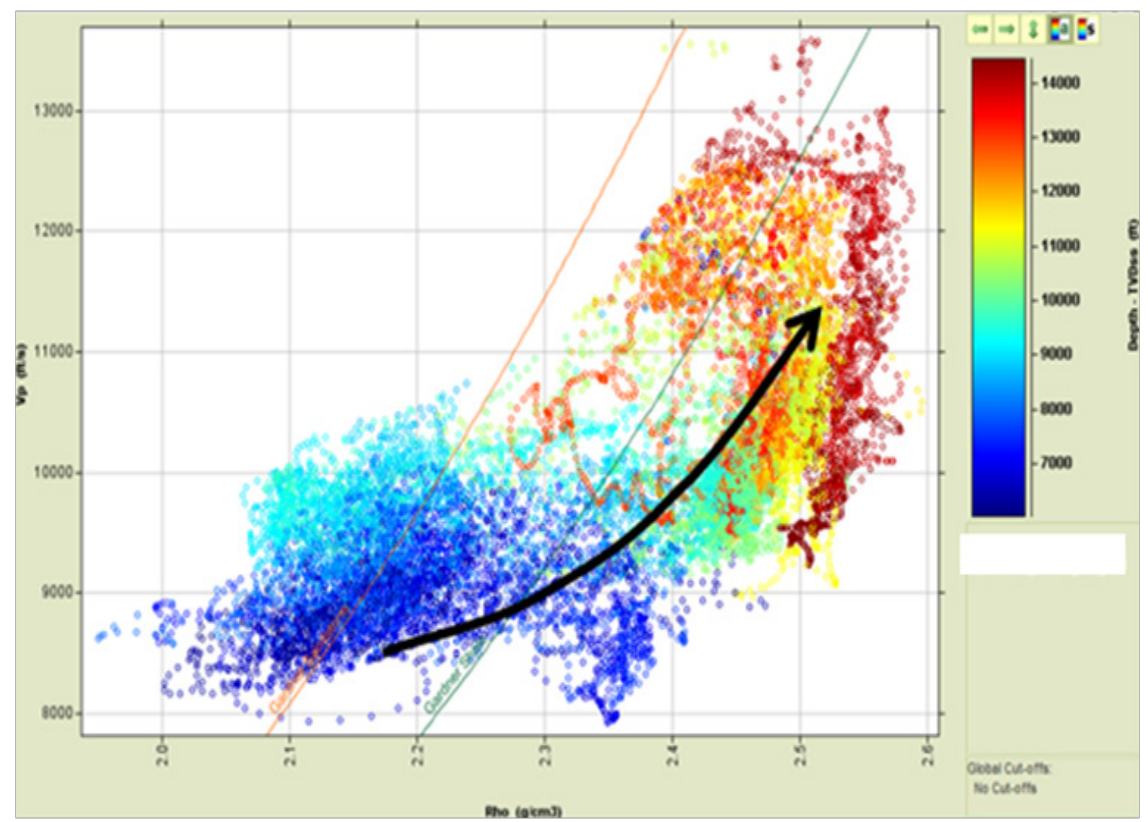

Figure 3 Trends of velocity versus depth which reveal patterns associated with the main processes which generate overpressure for Well A.

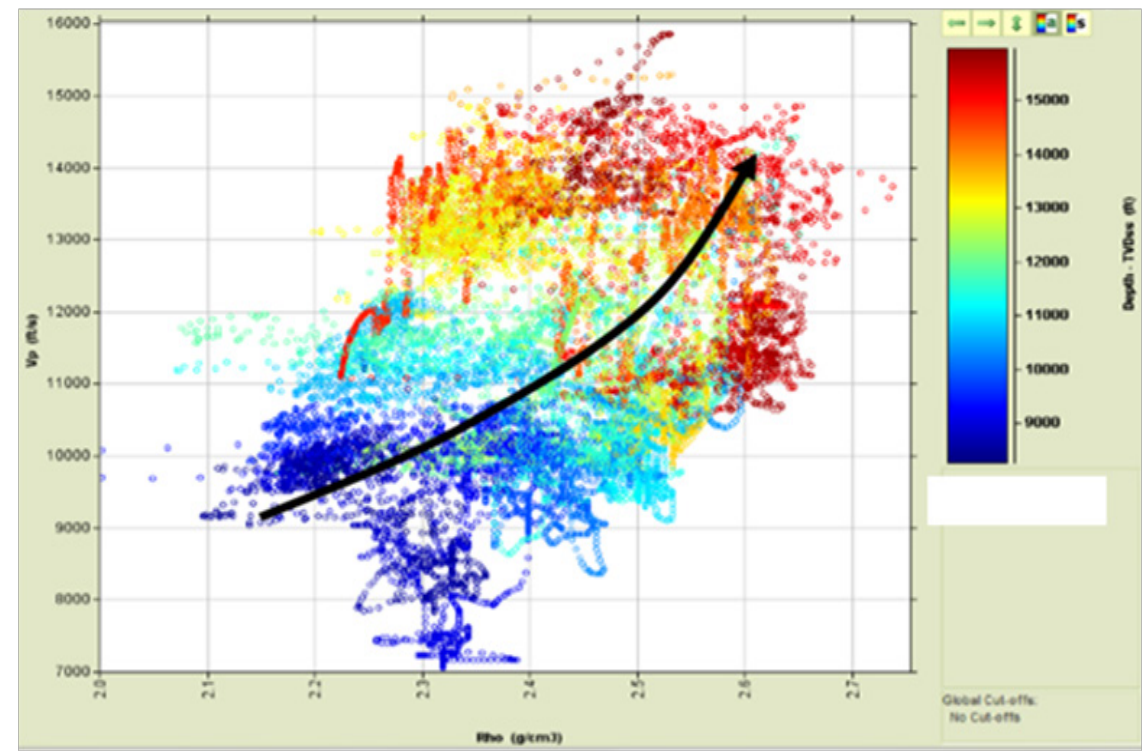

Figure 4 Trends of velocity versus depth which reveal patterns associated with the main processes which generate overpressure for Well B.

(Figure 5) (Figure 6) show the shale volume for well A and well $\mathrm{B}$, it is obvious that regions of shale lithology correspond to low resistivity and high density which is what is expected. The wells exhibit a dominantly shale/sand/shale sequence typical of the Niger delta formation. The wells were analysed in terms of fluid type and lithology. Shale lithologies were delineated by the high gamma ray value. Shale lithologies cause the deflection of acoustic impedance curve to the right and resistivity to the far left due to its high conductive nature. Regions showing low gamma ray, high resistivity, and low acoustic impedance are mapped as sand lithologies.

(Figure 7) (Figure 8), show a log suite were the over pressure estimation was carried out. These predictions were picked on a 1-D
PPP in shales. The log suites show Volume of shale, Resistivity log, Density log, Various Vp logs, OBP, Caliper log and Vs Logs. After the OBP, Vp Shale and NC compacted trend is calculated, the sampling of the values of these parameters are made manually along the vertical shale section with thick shale units. To achieve this, a log pane is loaded with derived log which aids manual tracking of the values within shale units. Using the measured pressure and the volume of shale as a guide, prediction points were picked. A graph of Pressures (MPP \& PPP) against depth was plotted for Well A and Well B. The predicted pressures compared favourably with measured pressure from both reservoir at depth and hydrostatic region in (Figure 9) (Figure 10) for Well A and Well B respectively. 


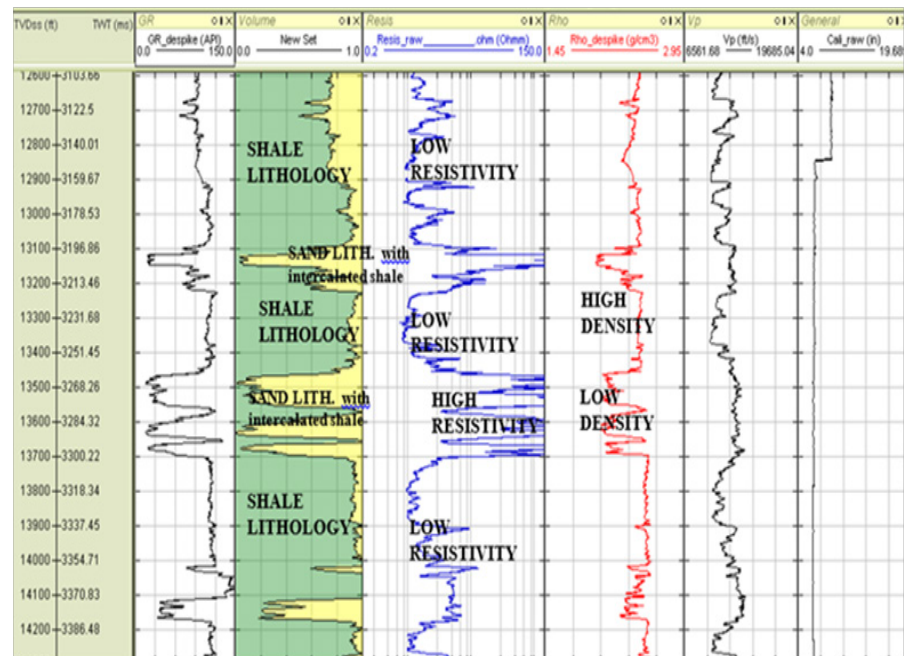

Figure 5 The logs show Shale volume generated from GR log for Well A.

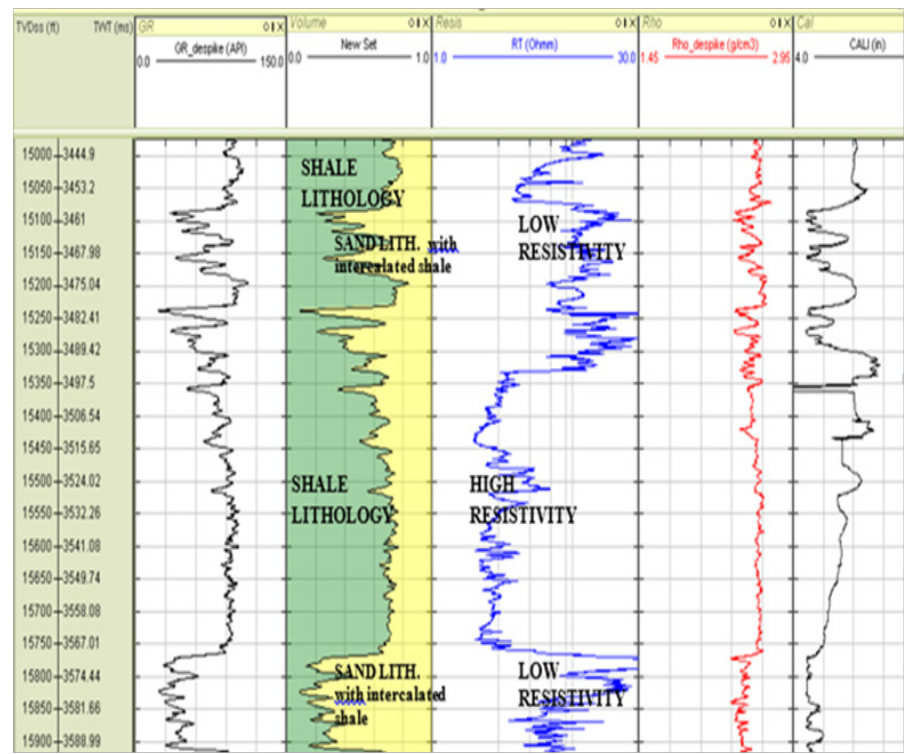

Figure 6 The logs show Shale volume generated from GR log for Well B.

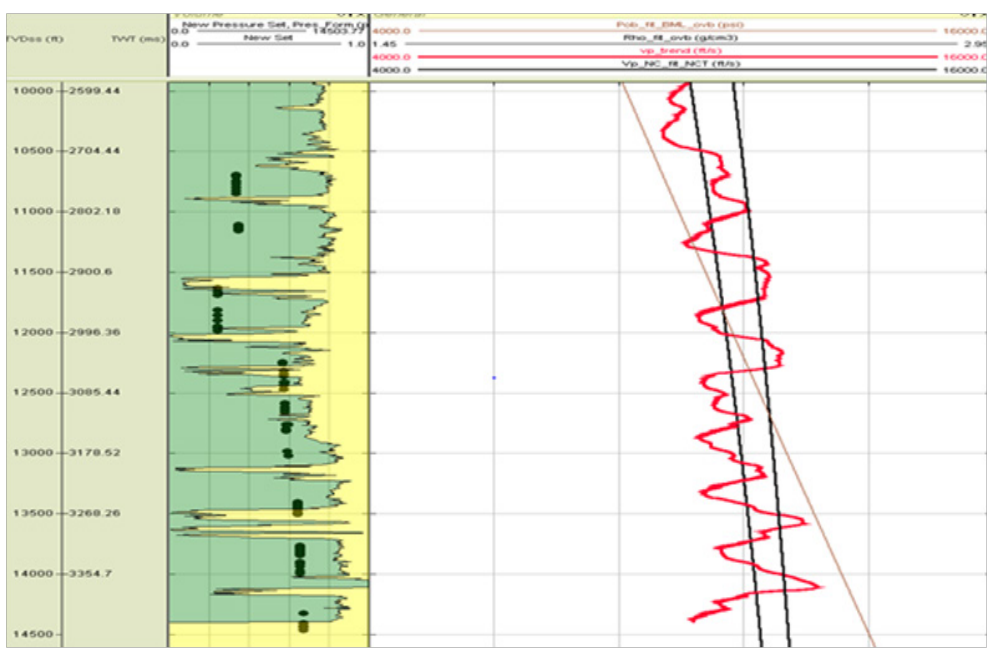

Figure 7 Well A panel were values for Pob, Rho_fit, Vp Shale trend and VP_NC_fit was picked. Figure 7 Well A panel were values for Pob, Rho_fit, Vp Shale trend and $V_{P} \_$NC_fit was picked. 


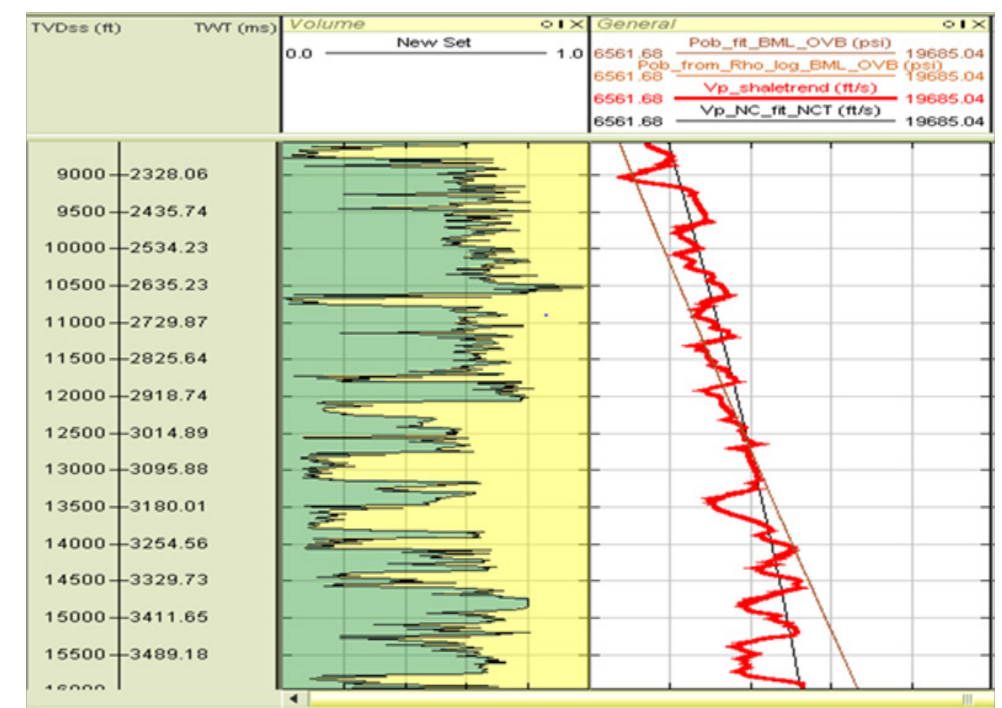

Figure 8 Well $A$ panel were values for Pob, Rho_fit, $V_{P}$ Shale trend and $V_{P} N N_{-}$fit was picked.

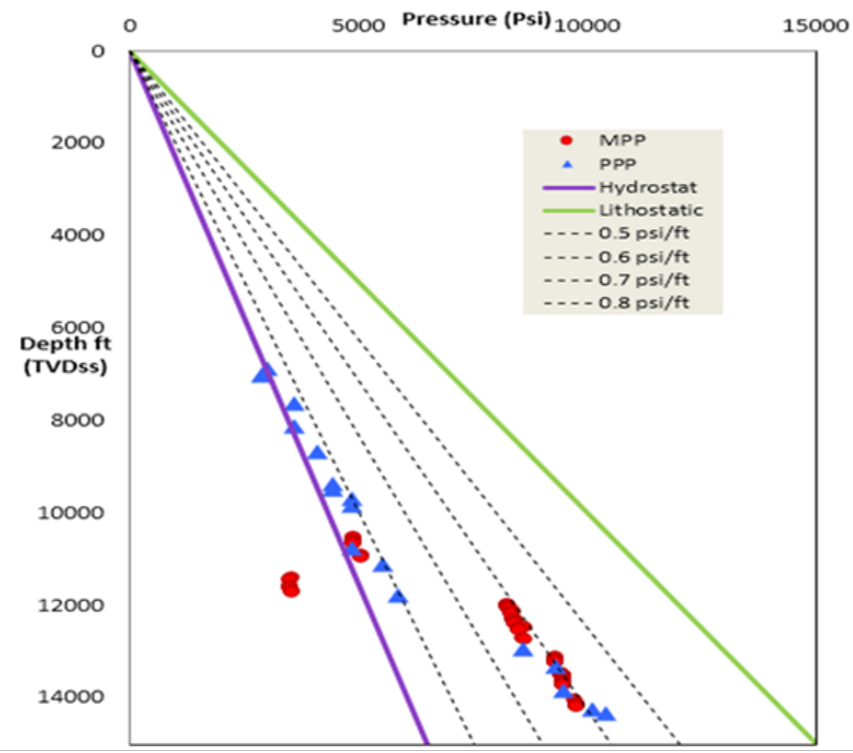

Figure 9 Pressure depth plot showing PPP and MPP of Well A.

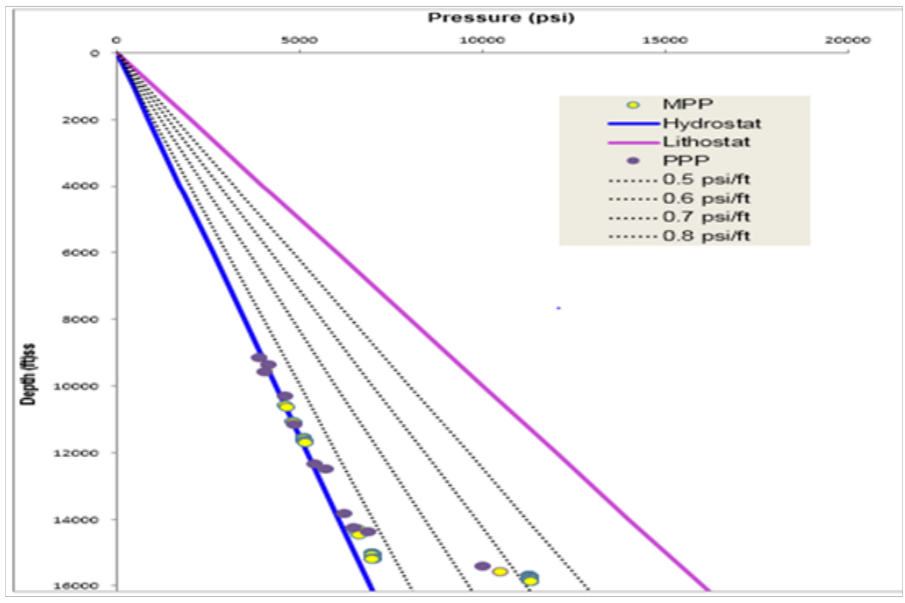

Figure 10 Pressure depth plot showing PPP and MPP of Well B. 


\section{Discussion}

Key logs required for the I-D pore pressure prediction were conditioned and quality checked to ensure accurate results. The geopressure evaluation is broad because its inclusion of measured pore pressure (MPP) values achieved from the repeated formation tests (RFTs). The two wells under review are of medium over pressured at all depths, since the pressure that is equal to normal in Niger Delta are $0.435 \mathrm{psi} / \mathrm{ft}$ for fresh water and $0.465 \mathrm{psi} / \mathrm{ft}$ for saline water.

Well B maintains normal pressure until 14,000ft depth were we observe the medium geopressure of less than $0.60 \mathrm{psi} / \mathrm{ft}$. High geopressure regime was observed in all the wells, when we evaluate the effect of established models with the log responses. The established empirical models correlates with the measured geopressure regime at the two bore hole locations and this confirms the suitability of the model in the study location (Figure 10). For well A, the arrival of medium geopressures regime $(<0.60 \mathrm{psi} / \mathrm{ft})$ begins at $11,500 \mathrm{ft}$ (Figure 9 ), since there is deviation of the normal compaction trend.

At well B, the top of the overpressure at this well is observed at depth beyond $1500 \mathrm{ft}$ and it is mild (not up to $8 \mathrm{psi} / \mathrm{ft}$ ) (Figure 10). The result as indicated in Figure 4 also shows that mechanism of this overpressure is not only disequilibrium compaction. Unloading mechanism is another cause of the presence of overpressure in this well. At well A, the onset of geopressure is at a depth of about $12,000 \mathrm{ft}$. The implication of adopting Eaton's exponent five is that the disquilibrum compaction might not be the only mechanism responsible for geopressure regime in the study location (Figure 3). In this study, Fracture pressures and gradients have been estimated using the Ben Eaton mode. Though, no Leak Off Test (LOT) data was available for comparison, the results obtained show that the shale at all the well locations possess a reasonable retention capacity. The seal in the two wells have good retention capacities hence, good trap integrity (or drilling margin) except at higher depths in well A and B. It was evaluated by adopting Gaarenstroom et al. (1993) definition of retention capacity.At a depth of $1096.81 \mathrm{ft}$ in well A, the cap rock (shale seal) lacks integrity. At this depth, the formation pressure is very close or equal to the fracture pressure which is the minimum effective stress on the formation. The implication is that drilling at this depth will fracture the cap rock (shale) and leads to hydrocarbon leakage (Figure 11). Also drilling well B at a depth of $12626 \mathrm{ft}$ or beyond will lead to seal failure. The fluid pressure at this depth is very close to the fracture pressure. Fluid pressures which are close to the fracture gradient tend to occur where either a secondary overpressure mechanism operates (such as gas expansion) or deep overpressures are conveyed to shallower levels, for example along a tilted reservoir (Figure 12).

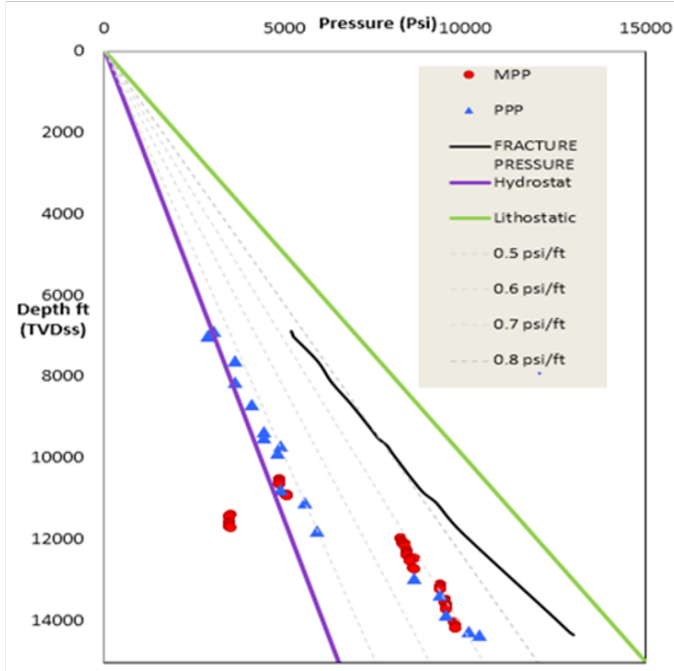

Figure II Pressure depth plot showing MPP, PPP and Fracture gradient of well A.

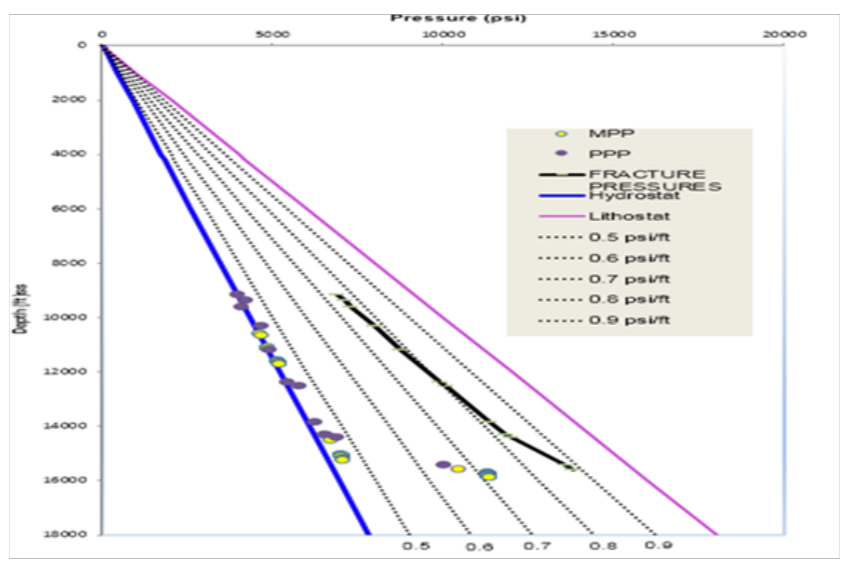

Figure 12 Pressure depth plot showing MPP, PPP and Fracture gradient of well B. 


\section{Conclusion}

Overpressures and fracture pressure gradients using well logs from two (2) exploratory wells in Niger Delta field was estimated and the fracture pressures at the well locations were evaluated in order to check the integrity of the seal or cap rock covering the hydrocarbon in the reservoir. The overburden stress or pressure (OBP), normal compaction trends (NCT) and shale velocity trends have been generated from the volume of shale, density, gamma, resistivity and sonic logs. Prediction points were picked at depths with thick shale and also on areas of no washouts zone. Over pressure regime was estimated using Eaton's exponent of 5 and also compared with measured pressures (RFT data) from the same wells. Since Eaton's exponent of 5 was able to predict pore pressures that compared reasonably with the measured pressure, it implies that other mechanisms than disequilibrium compaction must have contributed to the presence of overpressures in the areas. Overpressure estimations were done by observing the deviations of the predicted fluid pressures from the hydrostatic pressure line.

The predicted fluid pressures and generated overburden pressures have been used to estimate fracture pressure gradients using the Ben Eaton's Model. These fracture gradients and the predicted formation pressures are factors used to estimate the retention capacity of the cap rock (Shale seal) and the integrity of the seal. The results obtained from the analysis reveal that the two wells under review were of medium over pressured at all depths. The models used in this study were appropriate, since the predicted geopressure was related to the measured pressure within the well locations. The study also show that the seal in the two wells have good retention capacities hence, possess reasonable trap integrity (or drilling margin) except at higher depths in well.

\section{Acknowledgments}

None.

\section{Conflict of interest}

There is no conflict of interest in any way about the paper.

\section{References}

1. Kufre U, Mfon A, Okechukwu A. Estimation of over pressure in onshore Niger Delta using wire line data. International Journal of Science and Research. 2015;4(5):2780-2784.

2. Fooshee JS. The development of a pore pressure and fracture gradient prediction models for the Ewing Banks 910 area in the Gulf of mexico. Published MSc thesis, Petroleum Engineering, Louisiana University, USA; 2000.

3. Swarkbrik RE, Osborne MJ. Mechanisms that generate abnormal pressures: an over view. In: Law BE, Ulmishek GF, editors. Abnormal pressures in hydrocarbon environments: AAPG memoir. 1998;70:13-34.

4. Evamy BD, Haremboure J, Kamerling P, et al. Hydrocarbon habitat of Tertiary Niger Delta. American Association of Petroleum Geologists Bulletin. 1978;62(1):277-298.

5. Osborne MJ, Swarbrick RE. Mechanisms which generate overpressure in sedimentary basins: A revaluation. AAPG Bulletin. 1997;81(12):1023-1041.

6. Holbrook P, Robertsln HA, Hauck ML. Method of Determining Pore Pressure and Horizontal Effective Stress from Overburden and Vertical Effective Stress US Patent,4981037. 2002.

7. Lahann R, McCarty D, Hsieh J. Influence of Clay Diagenesis on Shale Velocities and Fluid Pressure. Offshore Technology Conference, USA; 2001.

8. Bowers G. Determining an Appropriate Pore-Pressure Estimation Strategy. Offshore Technology Conference, USA; 2001.

9. Eaton BA. The effects of overburden stress on geopressure prediction from well logs. Journal of Petroleum Technology. 1972;24:929-934.

10. Swarbrick RE, Osborne MJ, Yardley GS. Comparison of overpressure magnitude resulting from the main generating mechanisms. $A A P G$ Memoir. 2002;76:1-12. 